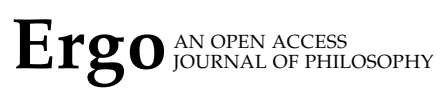

\title{
Names, Masks, and Double VISION
}

\author{
MICHAEL RIEPPEL \\ Syracuse University
}

\begin{abstract}
Cumming (2008) argues that his Masked Ball problem undermines Millianism, and that we must instead treat names as variables. However, although the Masked Ball does pose a problem for the Millian given a standard view about the meaning of 'believes', that view faces difficulties for independent reasons. I develop a novel "neo-Kaplanian" attitude semantics to address this problem, and go on to show that with this alternative semantics in hand, the Millian is quite capable of accounting for the Masked Ball.
\end{abstract}

\section{Introduction}

The behavior of proper names in belief reports is notoriously bedeviling. Frege's Puzzle about the non-substitutability of coreferring names is the classic example. A problem of more recent origin is Cumming's (2008) Masked Ball:

Rosaline, Maria, and Katherine are going to a masked ball. Each lady anticipates (tepidly) the attentions of a different suitor, and each suitor has given his lady a favor to wear, by which he hopes to recognize her during the masque. The ladies, with malice aforethought, decide to swap favors and so cause the suitors to 'woo contrary'. (Cumming 2008: 529)

The exchange of favors is such that Rosaline is mistaken for Maria, Maria for Katherine, and Katherine for Rosaline. Now consider the following pair of reports concerning Rosaline's suitor Biron:

(KR) Biron thinks Katherine is Rosaline.

(RK) Biron thinks Rosaline is Katherine.

On the most natural readings of these reports, (KR) is true whereas (RK) is false (Biron thinks Rosaline is Maria, not Katherine). It thus looks like symmetry inferences can fail in belief contexts, even if the subject to whom the belief is ascribed is, as we may assume, perfectly rational. 
Cumming (2008) argues that this phenomenon undermines Millianism. The Millian, who views names as individual constants that rigidly pick out their bearers across possible worlds, does not have the semantic resources, Cumming argues, to account for the apparent symmetry failure exhibited in the Masked Ball. To account for the phenomenon, he claims, we instead need to go variabilist and treat proper names as variables whose reference is determined by an assignment function.

I shall argue that the Masked Ball fails to undermine the Millian position. As we'll see in the next section, the nonequivalence of (KR) and (RK) suggests that names participate in a de re/de dicto ambiguity. What Cumming demonstrates is that this phenomenon undermines a certain composite view, one that combines a Millian semantics for names with a standard semantics for belief reports, according to which 'believes' is a modal necessity operator. He concludes that we should abandon both components of this composite view. But this conclusion goes beyond what has been demonstrated. Perhaps the fault lies not with Millianism, but just with the standard semantics for belief reports.

Indeed, that semantics faces difficulties with de re reports for independent reasons, stemming from Quine's (1956) Double Vision scenario. To assess what impact the Masked Ball has on Millianism, we would therefore do well to address this latter problem first. To that end, I develop a novel "neo-Kaplanian" semantics for belief reports that is able to accommodate Quine's Double Vision cases. I then show that with this alternative semantics in hand, the Millian in fact can, pace Cumming, resolve the Masked Ball problem. By way of conclusion, I then show that the neo-Kaplanian furthermore avoids a trivialization objection that Pickel (2015) presses against Cumming's proposal.

The structure of the paper is as follows. In the next section I present Cumming's analysis of the Masked Ball problem and the argument against Millianism he develops on its basis. In Section 3 I review the difficulty Quine's (1956) Double Vision scenario poses for the traditional attitude semantics Cumming invokes in his argument, and then (in Sections 4 and 5) develop a novel alternative semantics inspired by Kaplan's (1968) treatment of the Double Vision problem. Moving to Section 6, I show that this neo-Kaplanian semantics allows the Millian to account for the truth conditional difference between the Masked Ball reports (KR) and (RK). I conclude, in Section 7, by showing how the proposal avoids the trivialization objection Pickel (2015) raises against Cumming (2008).

\section{De Re, De Dicto, and the Masked Ball}

Quine (1956) illustrates the de re/de dicto distinction at the hand of the following example: 
(1) Ralph believes someone is a spy.

On one reading, the de dicto reading, this just says that Ralph thinks that there are spies. On another reading, the de re reading, Ralph's belief is less platitudinous: there is some particular individual he takes to be engaged in espionage. Quine proposes the following regimentations for the two readings: ${ }^{1}$

(2) a. De dicto: Ralph believes $\exists x$ ( $x$ is a spy).

b. De re: $\exists x$ (Ralph believes $x$ is a spy).

with the quantifier taking narrow scope under 'believes' on the de dicto reading and wide scope over 'believes' on the de re reading.

Cumming (2008) points out that something like this seems to be going on in the Masked Ball reports as well. In particular, he notes that the puzzling symmetry failure observed in the Masked Ball can also be generated with descriptions. Suppose Katherine entered the ballroom first, but that Biron mistakenly thinks she entered last. In this situation, the first of the following two reports rings true whereas the second doesn't:

(FL) Biron thinks the person who entered first is the person who entered last.

(LF) Biron think the person who entered last is the person who entered first.

We can explain this apparent symmetry failure by appeal to the kind of ambiguity invoked by Quine. Intuitively, (FL) can be read as saying that the woman who entered first is such that Biron thinks she entered last, whereas (LF) can be read as saying that the woman who entered last is such that Biron thinks she entered first. In both sentences, the embedded subject is interpreted de re, taking scope over 'thinks', whereas the second description is interpreted de dicto, inside the scope of 'thinks'.

This proposal can be fleshed out as follows. We begin with the textbook meaning for 'believes' (or 'thinks'): ${ }^{2}$

1. This is Quine's initial regimentation of the de re reading. He ultimately abandons it because it involves quantification into a context that is referentially opaque (that being one lesson of his Double Vision scenario, which I discuss in the next section). Roughly, the worry is that the truth value of the open sentence 'Ralph believes $x$ is a spy' is not settled simply by assigning an object to the variable, since such reports appear also to be sensitive to the way that object is specified. He concludes from this that (objectually) quantifying into an opaque context makes no sense.

2. I call this the "textbook" meaning because it is the one presented in Heim and Kratzer's 1998 Section 12.3) textbook Semantics in Generative Grammar. The analysis of course goes back to Hintikka (1962), and is widely adopted in formal semantics and epistemic logic. Though I will throughout this paper work within a possible worlds framework, difficulties in the vicinity of those I'll be discussing also beset other views about belief reports, and I will occasionally comment on how some of them might play out in frameworks that appeal to neo-Russellian 
$\llbracket$ believes $\rrbracket^{w, g}=\lambda p \cdot \lambda x\left[\forall w^{\prime} \in B_{x}^{w}: p\left(w^{\prime}\right)=1\right]$

according to which 'believes' introduces universal quantification over the set of worlds $B_{x}^{w}$ compatible with the subject $x^{\prime}$ s beliefs in $w .{ }^{3}$ If both of the descriptions in (FL) and (LF) remain in situ under 'believes', we get the following truth conditions: ${ }^{4}$

(3) a. $\llbracket(\mathrm{FL})_{d d} \rrbracket^{w, g}=1$ iff $\forall w^{\prime} \in B_{\text {Biron }}^{w}: \iota x\left[\right.$ EnteredFirst $\left.\left(x, w^{\prime}\right)\right]=\iota x\left[\right.$ EnteredLast $\left.\left(x, w^{\prime}\right)\right]$

b. $\llbracket(\mathrm{LF})_{d d} \rrbracket^{w, g}=1$ iff $\forall w^{\prime} \in B_{\text {Biron }}^{w}: \iota x\left[\right.$ EnteredLast $\left.\left(x, w^{\prime}\right)\right]=\iota x\left[\right.$ EnteredFirst $\left.\left(x, w^{\prime}\right)\right]$

On this de dicto interpretation, the two reports cannot diverge in truth value: if the person who entered first in each belief world is identical to the one who entered last in that belief world, then the person who entered last in each belief world is identical to the one who entered first in that belief world.

To capture the reading on which the sentences receive the truth conditions we're after, we let the description in the embedded subject position move to take scope over 'thinks'.5 Syntactically, this would look as follows in the case of (FL):

(4)

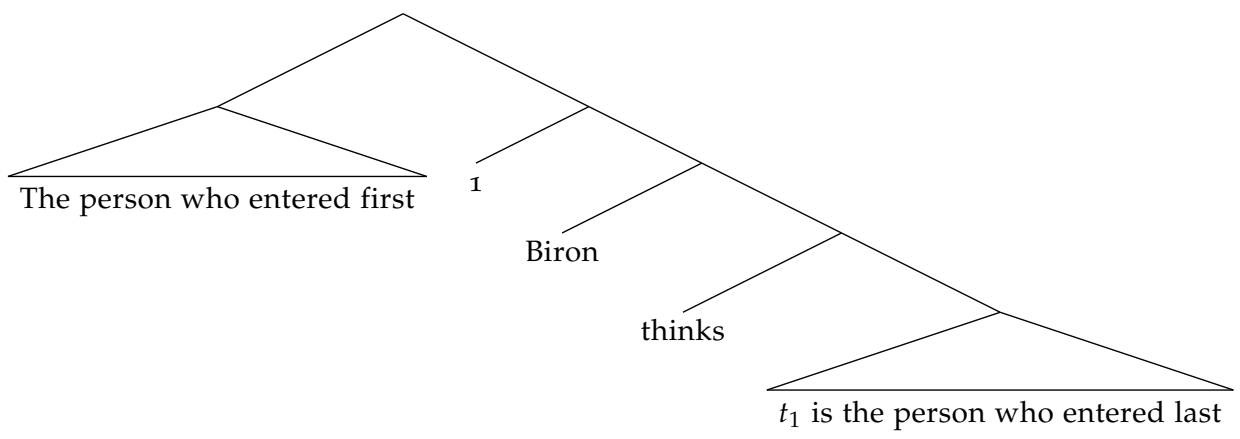

Since the question of how this structure delivers the desired truth conditions will be important as we continue, I will review this in some detail. What has

structured propositions.

3. A note on the notation: lambda terms denote functions, with the $\lambda$-abstractors indicating the arguments of the function. Thus:

$$
\lambda p . \lambda x\left[\forall w^{\prime} \in B_{x}^{w}: p\left(w^{\prime}\right)=1\right]
$$

is a function of two arguments, the first of which, $p$, is a proposition (denoted by the complement clause of 'believes') and the second of which, $x$, is an individual (denoted by the subject term). This function then yields the value True, or 1 , at a world $w$ just in case $p$ and $x$ are such that $\forall w^{\prime} \in B_{x}^{w}: p\left(w^{\prime}\right)=1$, that is, just in case the proposition $p$ is true at each world $w^{\prime}$ in $x^{\prime}$ s belief set $B_{x}^{w}$.

4. Following Cumming (2008), I am here adopting a Fregean treatment of descriptions, according to which they are individual-denoting rather than being quantifier phrases as per Russell (1905). The choice isn't important for present purposes-the points I go on to make go through on either view.

5. Again, compare Heim and Kratzer's 1998 Section 12.3, Ex. 1) discussion of the de re/de dicto distinction. 
happened, again, is that the description 'the person who entered first' has moved from its embedded position under 'thinks' and been adjoined to the top of the tree. The position that the description used to occupy is now occupied by a trace $t_{1}$, that is, by a variable. This means that the clause under 'thinks' is now an open sentence, and that we therefore have to pay attention to the variable assignment relative to which the embedded clause is evaluated.

This is where the binder ' 1 ' that occurs between the raised description and the rest of the tree comes in to play. Semantically, we can think of it as effecting a "shift" in the variable assignment so that any variable subscripted with ' 1 ' that occurs below the binder gets as its value the individual denoted by the raised description at the actual world. For example, if we begin our evaluation with a contextually provided variable assignment $g$, the effect of the binder is to shift this assignment to one that differs from the contextual assignment at (or at most at) the first index:

$$
g\left[\begin{array}{l}
1 \mapsto \text { Simon } \\
2 \mapsto \text { Oscar } \\
\vdots
\end{array}\right] \quad \Longrightarrow \quad g\left[\begin{array}{l}
1 \mapsto \text { ix }[\text { EnteredFirst }(x, w)] \\
2 \mapsto \text { Oscar } \\
\vdots
\end{array}\right]
$$

The portion of the tree underneath the binder then gets evaluated with respect to this shifted assignment. This means that the trace $t_{1}$ will get as its value the individual to which the assignment maps the index 1 , i.e. to the individual the description denotes at the actual world $w$. Given raised structures of this sort, our two sentences now receive the following truth conditions:

(5) a. $\llbracket(\mathrm{FL})_{d r} \rrbracket^{w, g}=1$ iff $\forall w^{\prime} \in B_{\text {Biron }}^{w}: \iota x[$ EnteredFirst $(x, w)]=\iota x\left[\right.$ EnteredLast $\left.\left(x, w^{\prime}\right)\right]$

b. $\llbracket(\mathrm{LF})_{d r} \rrbracket^{w, g}=1$ iff $\forall w^{\prime} \in B_{\text {Biron }}^{w}: \iota x[$ EnteredLast $(x, w)]=\iota x\left[\right.$ EnteredFirst $\left.\left(x, w^{\prime}\right)\right]$

These differ from the earlier truth conditions in that the subject description is now evaluated at the actual world $w$, rather than at Biron's belief worlds $w^{\prime}$. The truth conditions recorded in (5a) require that the unique person who entered first in the actual world w-that is, Katherine-be identical in each of Biron's belief worlds $w^{\prime}$ to the person who entered last in that belief world $w^{\prime}$. The truth conditions recorded in (5b), on the other hand, require that the unique person who entered last in the actual world-someone other than Katherine-be identical to the person who entered first in Biron's belief worlds $w^{\prime}$. On this de re interpretation, the truth conditions of the two reports therefore differ, as we wanted.

Cumming's (2008) point, now, is that the Millian cannot provide a parallel explanation of the apparent symmetry failure in the Masked Ball reports, which involve proper names rather than descriptions. These reports also seem to involve interpreting the embedded subject outside the scope of 'thinks'. Thus (KR) 
can be glossed as saying that Katherine is such that Biron thinks she's Rosaline and (RK) as saying that Rosaline is such that Biron thinks she's Katherine. ${ }^{6}$ But according to the Millian, interpreting a name outside, rather than inside, the scope of 'thinks' has no semantic effect: since names, unlike descriptions, are rigid, they denote the same thing whether evaluated at the actual world or a belief world. The Millian, in other words, delivers the following equivalent truth conditions for the Masked Ball reports:

(6) a. $\llbracket(\mathrm{KR}) \rrbracket^{w, g}=1$ iff $\forall w^{\prime} \in B_{\text {Biron }}^{w}$ : Katherine $=$ Rosaline.

b. $\llbracket(\mathrm{RK}) \rrbracket^{w, g}=1$ iff $\forall w^{\prime} \in B_{\text {Biron }}^{w}$ : Rosaline $=$ Katherine.

irrespective of whether the names in the subject position are interpreted inside or outside the scope of 'thinks'. Cumming therefore concludes that Millians "do not have the semantic resources to explain these data" (2008: 531).7

Cumming's positive proposal involves a number of steps. First, he replaces Millianism with variabilism, according to which names are variables and thus receive their semantic values from an assignment function. Treating names as variables won't on its own resolve the problem, however, since variables are just as rigid across possible worlds (relative to a fixed assignment) as Millian names are. Cumming's second step, therefore, is to modify the semantics for the attitude verb so that 'believes' is no longer analyzed as a box operator ' $\square$ ' that just shifts the world of evaluation, but rather an operator ' $\square$ ' that also shifts the variable assignment. In particular, ' $\square$ ' acts as a universal quantifier over assignmentworld pairs, with the world parameter representing the world as Biron takes it to be and the assignment representing "the reference relation as Biron [or more

6. Cumming 2008 Footnote 12) points out that given an appropriate contextualization, another reading is possible on which the name in the embedded subject position is interpreted within the scope of 'thinks' and the second name is interpreted outside its scope. Presumably there are also readings (false ones, given the Masked Ball story) on which both names are interpreted de dicto. I throughout focus on the salient reading which Cumming presses against the Millian.

7. Although I have here followed Cumming in presenting the problem faced by the Millian in a possible worlds framework, a similar difficulty arises with neo-Russellian structured propositions. The open sentence ' $t_{1}$ is Rosaline', for example, will express the same neoRussellian proposition (relative to an assignment that maps 1 to Katherine) as 'Katherine is Rosaline', so interpreting a name inside or outside the scope of 'thinks' again has no effect. One difference is that the structured propositions $\langle\mathrm{k},\langle=, \mathrm{r}\rangle\rangle$ and $\langle\mathrm{r},\langle=, \mathrm{k}\rangle\rangle$ respectively expressed by the complement clauses in (KR) and (RK) are distinct, so the neo-Russellian is able to assign distinct truth conditions to our two Masked Ball reports. The difficulty of explaining how Biron could rationally believe one but not the other of these two propositions remains, however. Propositional guises of the sort appealed to by neo-Russellians like Salmon (1986) and Braun (1998) don't seem to help, for example. Suppose we think of propositional guises as sentence-like entities (perhaps in a language of thought), and hold that Biron believes $\langle\mathrm{k},\langle=$, $r\rangle\rangle$ in virtue of accepting the sentence ' $k=r^{\prime}$. If he has his logical wits about him, he will infer and accept the sentence ' $r=k^{\prime}$ ', and thus count as believing the proposition $\langle r,\langle=, k\rangle\rangle$ as well. 
generally, the subject of the report] sees it" (Cumming 2008 531). Lastly, Cumming proposes that readings on which names are interpreted outside the scope of 'believes' be captured via a version of Kaplan's (1968) account of de re reports, according to which such reports only partially specify the content of the ascribed belief (more on Kaplan's account below). In particular, (KR) and (RK) are regimented as follows by Cumming (2008):

(7) (KR) $\Sigma u\left(u=x_{k} \wedge \unrhd_{B} u=x_{r}\right)$

(RK) $\Sigma u\left(u=x_{r} \wedge \unrhd_{B} u=x_{k}\right)$

Here the variable ' $x_{k}$ ' represents the name 'Katherine' and ' $x_{r}$ ' the name 'Rosaline', and ' $\Sigma u^{\prime}$ is a (existential, or "particular") substitutional quantifier that binds a substitutional variable $u$ which takes ordinary, objectual variables as its substituends. The substitutionally quantified (KR), for example, will be true if there is some ordinary variable ' $v$ ' such that the result of substituting ' $v$ ' for ' $u$ ' (and erasing ' $\Sigma u^{\prime}$ ) yields a true sentence.

The reader needn't worry if not all elements of the preceding sketch of Cumming's proposal are immediately clear. For our purposes, the important point is that the proposal involves three main ingredients: first, names are treated as variables, second, 'believes' is treated as an operator that shifts both the world and the variable assignment, and finally, de re reports are represented along broadly Kaplanian lines. With these elements in place, the truth conditions assigned to the Masked Ball reports according to Cumming's regimentations in (7) are roughly as follows: $(\mathrm{KR})$ is true iff there is some use of a name that actually refers to Katherine but that Biron takes to refer to Rosaline (or that corefers with ' $x_{r}$ at all the assignment-world pairs in Biron's doxastic set), and (RK) is true iff there is some use of a name that actually refers to Rosaline, but that Biron mistakenly takes to refer to Katherine (or that corefers with ' $x_{k}$ ' at all the assignment-world pairs in Biron's doxastic set). Cumming is thus able to account for the truth conditional difference between the pair of reports.

As I've said, I here want to pursue a different tack. As Cumming's positive proposal makes clear, the Masked Ball data pose a problem for a certain combination of views. In particular, no truth-conditional difference can result from interpreting a name outside rather than inside the scope of 'believes' if we hold, first, that names are individual constants that rigidly pick out their bearers, as per Millianism, and second, that 'believes' simply serves to shift the world of evaluation, as per the textbook semantics. Cumming (2008) proposes to deal with the problem by dropping both of these views: names must be treated as variables, and 'believes' as an operator that shifts the variable assignment. What I want to suggest is that the Masked Ball is amenable to a less radical solution. Perhaps the problem doesn't lie with Millianism, but simply with the textbook semantics for 'believes'. In fact, we need turn no further than Quine's (1956) fa- 
mous Double Vision scenario to see that this semantics faces problems with de re reports.

\section{Double Vision}

After introducing his example of the ambiguous 'Ralph believes someone is a spy', Quine offers the following background story:

There is a certain man in a brown hat whom Ralph has glimpsed several times under questionable circumstances on which we need not enter here; suffice it to say that Ralph suspects he is a spy. Also there is a gray-haired man, vaguely known to Ralph as rather a pillar of the community, whom Ralph is not aware of having seen except once at the beach. Now Ralph does not know it, but the men are one and the same .... (Bernard J. Ortcutt, to give him a name). (Quine 1956: 179)

Quine observes that in the context of this Double Vision scenario, it is appropriate to say both that Ralph believes that the man in the brown hat (glimpsed under questionable circumstances) is a spy, and that Ralph believes that the man at the beach (a pillar of the community) is not a spy. Quine argues that it is furthermore true to say, of this man Ortcutt, both that Ralph believes he is a spy, and that Ralph believes he is not a spy. The following pair of reports in other words are both true:

(8) a. Ralph believes Ortcutt is a spy.

b. Ralph believes Ortcutt is not a spy.

on a reading where the name 'Ortcutt' is interpreted de re, outside the scope of 'believes'. To accept both reports as true, Quine moreover claims, is not "to charge Ralph with contradictory beliefs" (Quine 1956. 182).

The textbook semantics cannot accommodate this judgment about the Double Vision scenario. On that semantics, the two de re reports receive the following truth conditions:

(9) a. $\forall w^{\prime} \in B_{\text {Ralph }}^{w}: \operatorname{Spy}\left(\right.$ Ortcutt, $\left.w^{\prime}\right)$

b. $\forall w^{\prime} \in B_{\text {Ralph }}^{w}: \neg S p y\left(\right.$ Ortcutt, $\left.w^{\prime}\right)$

These truth conditions are inadequate: they require both that Ortcutt be engaged in espionage at each of Ralph's belief worlds $w^{\prime}$, and that he also fail to be engaged in espionage at each of Ralph's belief worlds. Since no non-empty belief state can meet both conditions, the textbook semantics incorrectly predicts that our pair of reports represent Ralph as having logically incoherent beliefs. 
One could perhaps question Quine's judgments regarding his particular case, but it seems clear that the general problem is genuine. Take the following example:

In-Flight Movie: Ralph is asleep on a plane, and suddenly woken by someone kicking the back of his seat. He watches the in-flight movie for a few moments before falling back asleep. What he saw was Brando in A Streetcar Named Desire. On his return flight, the same thing happens, except now he sees Brando in The Island of Dr. Moreau. Ralph was barely awake, has no idea what he was watching, but thinks she saw two different menthe one he saw on the first flight was clearly better looking.

We can, it seems, truly report on this scenario as follows:

(10) Ralph thinks the lead actor in A Streetcar Named Desire and the lead actor in The Island of Dr Moreau are different people.

In doing so, we attribute a mistake to Ralph, but not any kind of logical incoherence. Notice that the report would be false on its de dicto reading: Ralph has no idea what he was watching, perhaps didn't even realize the men were acting, and has no beliefs that he would express using the descriptions 'the lead actor in A Streetcar Named Desire' or 'the lead actor in The Island of Dr. Moreau'. So the report must be read de re, that is, as saying that the lead actor in A Streetcar Named Desire (i.e., Brando) and the lead actor in The Island of Dr. Moreau (i.e., Brando again) are such that Ralph thinks they are different people. But on the textbook semantics this means that Ralph has an incoherent belief to the effect that Brando isn't self-identical. An unhappy result.

\section{The Kaplanian Proposal}

Let us therefore consider how we might revise the textbook semantics in light of this problem. Commenting on Quine's Double Vision scenario, Kaplan notes that "at first blush" it may appear that avoiding the result that (8a) and (8b) represent Ralph as doxastically incoherent "calls for the most intense kind of concentration and focus of interest" (1968: 191). He proposes to shed light on this puzzling situation by adopting a broadly Fregean view according to which belief reports represent subjects as bearing attitudes to sentences, or sentence-like entities, and de re reports specify the relevant sentence in an incomplete way. In particular, he recommends regimenting the de re readings of (8a) and (8b) as follows:

(11) a. $\exists \alpha[R(\alpha$, Ortcutt, Ralph $) \wedge$ Ralph believes $\ulcorner\alpha$ is a spy $\urcorner]$

b. $\exists \alpha[R(\alpha$, Ortcutt, Ralph $) \wedge$ Ralph believes $\ulcorner\alpha$ is not a spy $\urcorner]$ 
The quantifier ' $\exists \alpha^{\prime}$ is over expressions, and the relation $R$ imposes requirements on the expression $\alpha$ to the effect that it (i) denote Ortcutt, (ii) be a sufficiently "vivid" representation of Ortcutt, and (iii) be of Ortcutt for Ralph in a sense that guarantees that Ralph stands in some robust relation of acquaintance to Ortcutt. ${ }^{8}$

Thus (11a) says that there's some suitable representation $\alpha$ of Ortcutt such that Ralph believes the sentence that results from concatenating it with the predicate 'is a spy', and (11b) says that there's a suitable $\alpha$ such that Ralph believes the sentence that results from concatenating it with 'is not a spy'. The compatibility of the joint truth of (8a) and (8b) with Ralph's doxastic coherence is thus unproblematic: Ralph simply thinks of Ortcutt via two different representations, attributing spyhood to him relative to one and non-spyhood relative to the other. Put differently, our two reports do not imply:

$$
\exists \alpha[R(\alpha, \text { Ortcutt, Ralph }) \wedge \text { Ralph believes }\ulcorner\alpha \text { is a spy and } \alpha \text { is not a spy }\urcorner]
$$

that is, do not imply that there is any single representation relative to which Ralph attributes both spyhood and non-spyhood to Ortcutt.

Let us therefore consider how we might implement Kaplan's proposed solution a possible worlds framework. ${ }^{9}$ The "representations" quantified over in Kaplan's regimentations play the role of modes of presentation, or ways of thinking of objects. Such ways of thinking can be construed as picking out individuals at possible worlds, and in particular, as picking out different individuals at different worlds. Ralph, for example, has two ways of thinking of Ortcutt which,

8. Kaplan incorporates an acquaintance requirement to avoid the consequence that $S^{\prime}$ 'S (trivial) belief that the shortest spy is a spy suffices for the truth of the de re reading of ' $\mathrm{S}$ believes someone is a spy'. The requirement is controversial, however. Sosa (1970) offers a number of examples where representations that fail to be acquaintance-based seem eligible to witness the truth of de re reports. Further examples to similar effect are discussed by Bonomi (1995), Aloni (2005), and Hawthorne and Manley (2012) among others. See Kripke (2011) for criticism of Sosa's arguments. Moving forward, I will largely set aside the question of what role, if any, acquaintance should play in the truth conditions of de re reports, though I will return to threats of trivialization in the final two sections of this paper.

9. Another approach to Double Vision cases, often adopted by friends of neo-Russellian propositions (see, e.g., Salmon 1986. Chapter 8), invokes propositional guises, or ways of thinking of propositions rather than of individuals (as on Kaplan's proposal). On this view Ralph does believe a pair of contradictory propositions, but counts as doxastically coherent because he believes those propositions via two distinct guises. However, although this strategy resolves the Double Vision problem, it is less clear that it can be extended to cover the Masked Ball, as I remarked in Footnote 7 above. I suspect that something resembling the neo-Kaplanian account I go on to develop below could be implemented in terms of (quasi-) Russellian propositions as well, but a detailed investigation of the matter is beyond the scope of this paper. (I say "quasi" because the view would involve populating propositions with representations in place of individuals, somewhat along the lines of Russell's, 1903 Chapter 5, early theory of "denoting concepts.") See Yalcin (2015) for a suggestion about how Fregeans could implement a Kaplanian approach to de re reports. 
though they both pick out Ortcutt at the actual world, pick out different individuals at Ralph's belief worlds-one picks out a hat-wearing spy, the other a beach-strolling non-spy. In our semantics we can model different ways of thinking of objects using functions from worlds to individuals, or as they're standardly called, individual concepts. ${ }^{10}$

I will call the set of individual concepts under which a subject thinks about various individuals that subject's "conceptual repertoire."11 Put in these terms, Ralph's situation can be described by saying that Ralph's conceptual repertoire contains two individual concepts of Ortcutt, $m_{1}$ and $m_{2}$, and that whereas $m_{1}$ picks out a spy at each of Ralph's belief worlds, $m_{2}$ picks out a non-spy at each of his belief worlds. The truth conditions for the de re readings of our two reports that the neo-Kaplanian recommends are then as follows:

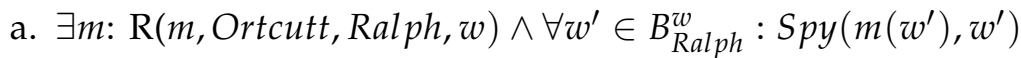
b. $\exists m: \mathrm{R}(m, \operatorname{Ortcutt}$, Ralph, w $) \wedge \forall w^{\prime} \in B_{\text {Ralph }}^{w}: \neg \operatorname{Spy}\left(m\left(w^{\prime}\right), w^{\prime}\right)$

with the relation $R$ understood as imposing the following requirements:

$R(m, y, x, w)$ iff (i) $m \in C_{x}^{w}$, i.e., $m$ is in $x^{\prime}$ s conceptual repertoire at $w$, and (ii) $m(w)=y$, i.e., $m$ picks out the res $y$ at $w \cdot{ }^{12}$

If we replace the truth conditions delivered by the textbook semantics with the truth conditions above, we vindicate the coherence of Ralph's belief state, as desired.

A problem remains, however. It is one thing to identify the truth conditions that we would like to associate with our pair of reports, but it's another matter to formulate a semantics for 'believes' that succeeds in delivering them. This turns out to be no trivial matter. The trouble, roughly speaking, stems from the fact

10. To say that we can model ways of thinking of individuals via functions from worlds to individuals is not to say that we must identify them with such functions. It suffices if ways of thinking determine individual concepts, though I will generally leave this qualification implicit in what follows.

11. I borrow this term from Aloni (2005), but the notion should not be confused with Aloni's more elaborate notion of a "conceptual cover." Aloni imposes certain restrictions on conceptual covers that I won't adopt for conceptual repertoires. Her first requirement is one of existence: a conceptual cover must contain a concept for every individual in the domain. She imposes this requirement in order to save the validity of existential generalization in non-modal contexts, since she construes the variables in her formal language as uniformly ranging over the elements of a conceptual cover. We won't be doing that, and won't impose the existence requirement. Her second requirement is one of uniqueness: a conceptual cover must contain at most one concept per individual. However, examples like In-Flight Movie from above suggest that multiple guises of an individual can be relevant to a single report. For further critical discussion of Aloni's restrictions, see Holliday and Perry (2014).

12. I here don't include the requirement that $m$ be a concept the subject acquired via acquaintance with the res for the reasons mentioned in Footnote 8 though it would of course be straightforward to supplement $R$ with such a requirement if it were needed. 
that the neo-Kaplanian truth conditions involve three entities: the subject of the belief, the res the belief is about, and the property the subject ascribes to that res. (13a), for example, requires that Ralph, the subject, ascribe the property of being a spy to Ortcutt, the res (relative to some individual concept). The question is how to achieve the needed "separation" between the res and the ascribed property, when, on the face of it, belief reports look like they just relate a subject to a proposition.

More concretely, consider how truth conditions like (13a) could be assigned to the original report (8a). It looks like 'believes' should introduce an existential quantifier over individual concepts, in particular over concepts meeting the requirements set out by $R$, among which is the requirement that the relevant concept $m$ be "of" the res, Ortcutt, that the belief is about. What is unclear is how Ortcutt could enter the truth conditions as a relatum of $R$ so as to impose this requirement on $m$. It seems that in order for him to play this role, the name 'Ortcutt' would have to function as an argument to the verb 'believes'. But on neither the surface syntax (on which 'Ortcutt' is embedded in the complement clause of 'believes') nor on the raised de re structure we considered in connection with the textbook semantics (on which 'Ortcutt' has moved to a position at the top of the tree above a variable binder) does the name function as an argument of 'believes'. The neo-Kaplanian therefore seems to require some "de re magic", as Schlenker (2004 190) puts it. ${ }^{13}$

One could of course simply postulate a special syntactic structure specifically for de re reports, on which 'believes' now combines with the three requisite arguments: the res term, the ascribed predicate, and the subject. But such a move raises several worries. As discussed by (Maier 2009: p. 459), this kind of purposebuilt de re structure has been criticized as syntactically implausible. Furthermore, this proposal requires us to postulate an ambiguity in 'believes'. De dicto reports would involve one variant of 'believes' that denotes the familiar two-place relation between a proposition an a subject, and de re reports a second variant that denotes a three-place relation between a res, an ascribed property, and a subject, perhaps along the following lines:
a. $\llbracket$ believes $_{d d} \rrbracket^{w, g}=\lambda p_{\langle s, t\rangle} \cdot \lambda x\left[\forall w^{\prime} \in B_{x}^{w}: p\left(w^{\prime}\right)=1\right]$

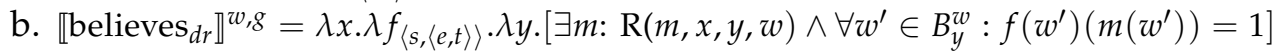

13. Cumming's 2008 proposal of course also faces this problem. Indeed, he faces not just the question of how to formulate a semantics for belief reports so that the res enters the truth conditions in the appropriate way, but also of how to get a substitutional quantifier to "bind" a substitutional variable within the scope of 'believes'. The difficulty is somewhat obscured in Cumming's discussion because he doesn't directly give a semantics for natural language belief reports, but instead offers formal regimentations of such reports, and then provides a semantics for the formal language in which these regimentations are cast. 
Indeed as Yalcin (2015) points out, things won't end there: the three-place variant of 'believes' only covers cases involving a single res, so multiply de re constructions will presumably require further variants taking additional arguments. None of this is particularly appealing. So although the neo-Kaplanian truth conditions enjoy evident advantages over those provided by the textbook semantics when it comes to Double Vision, it remains comparatively unclear what alternative semantics will actually let us secure those advantages.

\section{A Neo-Kaplanian Attitude Semantics}

Let me suggest a way to resolve this problem. ${ }^{14}$ Take the kind of raised de re structure we considered in connection with the textbook semantics, together with the truth conditions the neo-Kaplanian proposes:

(15) a.

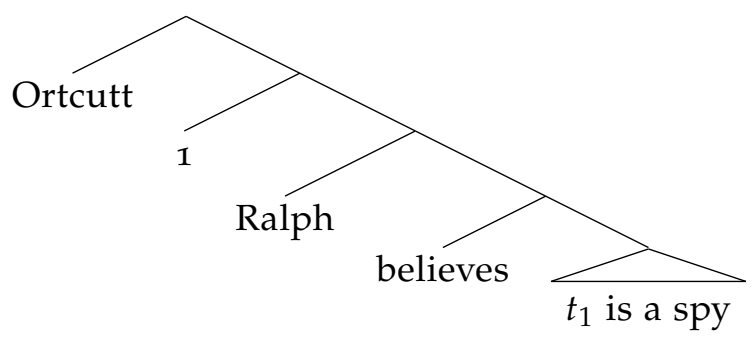

b. $\exists m: \mathrm{R}\left(m\right.$, Ortcutt, Ralph, w) $\wedge \forall w^{\prime} \in B_{\text {Ralph }}^{w}: \operatorname{Spy}\left(m\left(w^{\prime}\right), w^{\prime}\right)$

In the syntax the predicate 'is a spy' combines with the trace $t_{1}$, and in the truth conditions the property of being a spy is saturated by an individual concept (or more precisely, by the individual that this concept picks out at the relevant belief world). So it looks like the trace must somehow become associated with this concept. How can that go? Recall that as things stand, the assignment relative to which the portion of the tree below the variable binder is evaluated maps the trace $t_{1}$ to Ortcutt, an individual. But perhaps we can get what we're after if we allow 'believes' to alter this assignment at its first index so that $t_{1}$ becomes associated with an individual concept of Ortcutt rather than with Ortcutt himself. Of course we can't in general know which index in the variable assignment 'believes' will have to alter in this manner. But we can get around this by having 'believes' effect a global transformation of the assignment.

Various details will have to be sorted out, but let me illustrate the intuitive

14. The semantics I shall go on to articulate in certain respects resembles proposals made by Yalcin (2015), Ninan (2012), Santorio (2012), as well as Cumming's (2008) own proposal, insofar as 'believes' will shift not just the world but also the variable assignment. Other directions one could pursue include the dynamic semantics proposed by Maier (2009) or a view that postulates "concept generator" variables in the syntax, as proposed by Percus and Sauerland 2003) and Charlow and Sharvit 2014). 
idea. A variable assignment is like a lookup table that maps variable indices to individuals. Now suppose we take such a table and swap out the individuals with concepts of those individuals (where a concept $m$ is, again, "of" an individual $x$ relative to a world $w$ if $m(w)=x$ ), thereby obtaining what I'll call a conceptual transform of the original assignment:

$$
g\left[\begin{array}{l}
1 \mapsto \text { Ortcutt } \\
2 \mapsto \text { Alice } \\
3 \mapsto \text { Oscar } \\
\vdots
\end{array}\right] \quad \Longrightarrow \quad g^{\prime}\left[\begin{array}{l}
1 \mapsto m_{\text {Ortcutt }} \\
2 \mapsto m_{\text {Alice }} \\
3 \mapsto m_{\text {Oscar }} \\
\vdots
\end{array}\right]
$$

Given an ordinary assignment like $g[1 \mapsto o]$, there are various ways to generate a conceptual transform of it. ${ }^{15}$ Since Ralph, for example, has two concepts of Ortcutt, $m_{1}$ and $m_{2}$, one way to transform it is to swap $m_{1}$ for Ortcutt, giving us $g\left[1 \mapsto m_{1}\right]$, and another way is to swap $m_{2}$ for Ortcutt, giving us $g\left[1 \mapsto m_{2}\right]$. Now call a particular way of generating a transform a conceptual transformer. Such a transformer is a function $f$ that takes an ordinary assignment $g$ and yields a conceptual transform $f(g)$ of it. Thus $g^{\prime}$ from above is the result of applying a particular conceptual transformer to the original assignment $g$.

The thought, then, is that 'believes' introduces existential quantification over such transformers, in effect saying that there is some way to transform the assignment $g[1 \mapsto o]$ relative to which 'believes' is evaluated, so that the complement of 'believes' is true when evaluated relative to that transformed assignment (at every belief world $w^{\prime}$ ). Our neo-Kaplanian truth conditions will in other words now involve a quantifier over conceptual transformers, as in (16b), rather than one directly over individual concepts, as in the original truth conditions (16a).

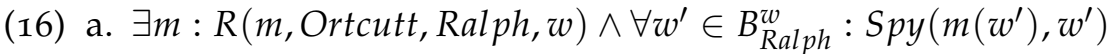

b. $\exists f: R(f$, Ralph, w $) \wedge \forall w^{\prime} \in B_{\text {Ralph }}^{w}: \operatorname{Spy}\left(f(g[1 \mapsto o])(1)\left(w^{\prime}\right), w^{\prime}\right)$

In the truth conditions (16a), $R$ imposes the requirement that $m$ be a concept of Ortcutt drawn from the subject Ralph's conceptual repertoire. In the revised truth conditions $(16 \mathrm{~b}), R$ requires, roughly, that the transformer $f$ produce assignments in which individuals have been swapped out with concepts of those individuals drawn from the subject Ralph's conceptual repertoire.

There are two minor complications. First, someone's conceptual repertoire may contain more than one concept of a given individual. Again, Ralph's conceptual repertoire $C_{\text {Ralph' }}^{w}$, for example, contains two individual concepts of Ortcutt. I'll use ' $C_{x}^{w}[y]$ ' to denote the subset of the subject $x^{\prime}$ 's conceptual repertoire comprised just of individual concepts of $y$ (that is, $C_{x}^{w}[y]=\left\{m \in C_{x}^{w} \mid m(w)=y\right\}$ ). So a transformer $f$ must produce a transform $f(g)$ that maps every variable index $i$

15. Here and in what follows, I use ' $g[1 \mapsto o]$ ' to abbreviate ' $g[1 \mapsto$ Ortcutt $]$ '. 
to some element of $C_{x}^{w}[g(i)]$. Second, our subject may not have a concept of every individual in the range of the original assignment $g$, so that $C_{x}^{w}[g(i)]$ is empty for some $i$. In such cases we'll just let $f(g)$ remain undefined at $i$. $R$ can thus be understood as minimally imposing the following requirements:

$R(f, x, w)$ iff for any ordinary assignment $g, f$ is such that (i) $f(g)$ is a function from domain $(g)$ to $C_{x}^{w}$, and (ii) for all $i \in \operatorname{domain}(g), f(g)(i) \in$ $C_{x}^{w}[g(i)]$ if $C_{x}^{w}[g(i)]$ is nonempty, and $f(g)(i)$ is undefined otherwise.

In the case of our sentence concerning Ralph, for example, the assignment $g[1 \mapsto$ $o$ ] relative to which 'believes' is evaluated maps the numerical index 1 to Ortcutt. So $R$ requires that $f(g[1 \mapsto o])$ map 1 to some concept of Ortcutt drawn from Ralph's conceptual repertoire. The truth-conditions in (16b) then say that the particular Ortcutt-concept to which our transform $f(g[1 \mapsto o])$ maps 1 is such as to pick out a spy at each of Ralph's belief worlds. (I say that the above-listed requirements are "minimal" to register that the neo-Kaplanian may want to supplement $R$ with further conditions, as I discuss below.)

So much for the target truth conditions. To deliver these truth conditions we replace the textbook entry (17a) for 'believes' with the neo-Kaplanian version $(17 \mathrm{~b})$

(17) a. $\llbracket$ believes $\rrbracket^{w, g}=\lambda p_{\langle s, t\rangle} \cdot \lambda x\left[\forall w^{\prime} \in B_{x}^{w}: p\left(w^{\prime}\right)=1\right]$

b. $\llbracket$ believes $\rrbracket^{w, g}=\lambda p_{\langle\gamma,\langle s, t\rangle\rangle} \cdot \lambda x\left[\exists f: \mathrm{R}(f, x, w) \wedge \forall w^{\prime} \in B_{x}^{w}: p\left(f(g)^{w^{\prime}}\right)\left(w^{\prime}\right)=1\right]$

Two points by way of explanation. First, the first argument $p$ of the denotation of 'believes' is now of type $\langle\gamma,\langle s, t\rangle\rangle$ rather than type $\langle s, t\rangle$, that is, it is a function from assignments and worlds to truth values (with $\gamma$ and $s$ the type of assignments and worlds, respectively) rather than one from just worlds to truth values. To borrow Cumming's (2008) terminology, 'believes' now expresses not a relation between agents and propositions, but one between agents and open propositions: functions from assignments to ordinary, "closed" propositions.

A second point is that the assignment $f(g)^{w^{\prime}}$ that is passed to the open proposition $p$ isn't the conceptual transform of $g$, but what I'll call the relativization (to the relevant belief world $w^{\prime}$ ) of the conceptual transform $f(g)$. This relativization is an "ordinary" assignment function (i.e., one mapping variable indices to individuals rather than to concepts) that is determined by the conceptual transform relative to the relevant belief world $w^{\prime}$. In general, given a conceptual transform $f(g)$, the relativization of $f(g)$ to $w$, written $f(g)^{w}$, is defined as follows: ${ }^{16}$

16. See Ninan (2012) and Santorio (2012) for similar moves. The proposed entry for 'believes' can consequently be thought of as a quantifier over world-assignment pairs similar to Cumming's (2008) ' $\square$ ': for any belief world $w$, the assignment it is paired with is $f(g)^{w}$. The report is then true if the open proposition expressed by the complement clause maps every such pair $\left\langle w, f(g)^{w}\right\rangle$ to truth. See Section 7 below for more on the relationship between our neo-Kaplanian belief operator and Cumming's ' $\square$ '. 
Relativization: for all $i$ and $w, f(g)^{w}(\mathrm{i})=f(g)(i)(w)$

The clausal complement of 'believes' is thus interpreted via the relativization of the transform to the relevant belief world. In effect, conceptual transformers play the role of mediating between the original assignment relative to which 'believes' is evaluated and the appropriately modified assignments relative to which the complement to 'believes' is then evaluated. Applying our lexical entry for 'believes' to the report $(15 \mathrm{a})$ then delivers the following truth conditions:

$$
\exists f: R(f, R a l p h, w) \wedge \forall w^{\prime} \in B_{\text {Ralph }}^{w}: \operatorname{Spy}\left(f(g[1 \mapsto o])^{w^{\prime}}(1), w^{\prime}\right)
$$

which, by Relativization, is equivalent to:

$$
\exists f: R(f, R a l p h, w) \wedge \forall w^{\prime} \in B_{R a l p h}^{w}: \operatorname{Spy}\left(f(g[1 \mapsto o])(1)\left(w^{\prime}\right), w^{\prime}\right)
$$

as desired. The complete derivation and further details about the semantics here appealed to are provided in the Appendix.

It is worth noting that this lexical entry for 'believes' is not peculiar to de re reports, and can equally well be applied to de dicto reports. The truth conditions we get for a de dicto reading of 'Ralph believes the man in the brown hat is a spy', for example, will be:

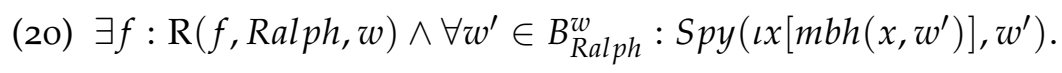

Since the complement to 'believes' contains no variable in this case, the quantifier over conceptual transforms is vacuous, and we essentially get the truth conditions we would get on the textbook semantics.

Multiply de re constructions that involve more than one externally bound variable in the complement clause are also handled: since 'believes' performs a global transformation of the assignment, every such variable will become associated with an appropriate concept. A related feature of the view is that any number of co-indexed variables in the complement clause of 'believes' must all become associated with the same concept. This has some potentially controversial upshots. For example, according to our semantics the two Double Vision reports (8a) and (8b) will not imply a report along the following lines:

(21) There is someone t $_{i}$ such that Ralph believes that he $e_{i}$ is a spy and he $e_{i}$ is not a spy.

This report contains a quantifier that binds a pair of coindexed variables in the complement clause, which must then be interpreted via the same concept. The truth of (21) therefore requires, roughly, that there be someone (viz., Ortcutt) to whom Ralph attributes both spyhood and non-spyhood relative to a single concept, much like Kaplan's example (12) from earlier. On the neo-Kaplanian view, (21) thus represents Ralph as doxastically incoherent in a way that the conjunction of 
the Double Vision reports (8a) and (8b) does not.

This result will be objectionable to some. Soames (1987), for example, argues that reports along the lines of (21) do not attribute incoherence to the subject. On his view, incoherence is only attributed to Ralph if the quantifier phrase is given narrow scope under 'believes', as in:

(22) Ralph believes that someone ${ }_{i}$ is such that he $e_{i}$ is a spy and he $e_{i}$ is not a spy.

I myself find the relevant judgments too delicate to come to a firm conclusion. To the extent that one is able to hear (21) as compatible with Ralph's doxastic coherence, this might be due to an implicit interpretation of the second conjunct as occurring under a separate belief operator. Suffice it to say that the status of reports like (21) is a point on which our Kaplanian view parts company with classic neo-Russellian views like Soames's (1987). ${ }^{17}$

\section{Revisiting Millianism and the Masked Ball}

Our neo-Kaplanian proposal offers us an improved treatment of de re reports that is able to deal with Quine's Double Vision problem. Though motivated on different grounds, it resembles Cumming's (2008) proposal in certain key respects. First, both treat de re reports as involving an incomplete specification of the as-

17. Soames's view is natural on an approach that appeals to propositional guises. The thought is that the propositions expressed by the complement clauses in (21) and (22) are both contradictions, but that whereas the former can be believed under a non-contradictory guise (so to speak) the latter cannot. Thanks to an anonymous referee for drawing my attention to this point of disagreement between the present proposal and that of Soames (1987). The referee notes that there are other binding-related phenomena that may cause trouble for the neo-Kaplanian. Suppose Ralph says to himself 'this German boy drew that Swedish boy's mother' while unbeknownst to himself pointing twice to the same French boy. The following report seems to have a true reading:

(i) Ralph believes that one of the French boys drew his (i.e., the French boy's) mother.

Here 'one of the French boys' must be read de re, which suggests the following parse:

(ii) One of the French boys 1 [ Ralph believes $t_{1}$ drew his ${ }_{1}$ mother ]

This again involves co-indexed variables in the complement clause, which must then be interpreted via the same concept (thus blocking the relevant true reading). Though this is a prima facie difficulty, the neo-Kaplanian might appeal an alternative parsing along the following lines:

(iii) One of the French boys 1 [ his ${ }_{1}$ mother 2 [ Ralph believes $t_{1}$ drew $t_{2}$ ] ]

to avoid coindexing. A full investigation of these matters is beyond the scope of this paper, however. See Charlow and Sharvit (2014) for discussion of examples like this. 
cribed belief, along the lines suggested by Kaplan (1968). Second, both proposals allow 'believes' to shift not just the world but also the variable assignment relative to which its complement is evaluated. If we turn from Double Vision back to the Masked Ball, however, we can now see that the neo-Kaplanian can account for it without taking Cumming's further step of abandoning Millianism in favor of variabilism.

Recall that according to the Millian, the names 'Katherine' and 'Rosaline' are rigid designators, respectively referring to Katherine and Rosaline at all possible worlds. Now suppose we allow the names in the embedded subject position of (KR) and (RK) to occur outside the scope of 'believes', as suggested by Cumming (2008). The Millian semantics for names together with our neo-Kaplanian semantics for 'believes' will now deliver the following truth conditions for these raised structures:

(23) a. (KR): $\llbracket\left[\right.$ Katherine [ 1 [Biron thinks $t_{1}$ is Rosaline $\left.\left.]\right]\right] \rrbracket^{w, g}=1$ iff «Biron thinks $t_{1}$ is Rosaline $\rrbracket^{w, g[1 \mapsto \text { Katherine }]}=1$ iff $\exists f: R(f$, Biron, $w) \wedge \forall w^{\prime} \in B_{\text {Biron }}^{w}: f(g[1 \mapsto$ Katherine $])(1)\left(w^{\prime}\right)=$ Rosaline

b. $(\mathrm{RK})$ : $\llbracket\left[\right.$ Rosaline [ 1 [Biron thinks $t_{1}$ is Katherine ] ] ] $\rrbracket^{w, g}=1$ iff $\llbracket$ Biron thinks $t_{1}$ is Katherine $\rrbracket^{w, g[1 \mapsto \text { Rosaline }]}=1 \mathrm{iff}$ $\exists f: R(f$, Biron, $w) \wedge \forall w^{\prime} \in B_{\text {Biron }}^{w}: f(g[1 \mapsto$ Rosaline $])(1)\left(w^{\prime}\right)=$ Katherine

Given these truth conditions, the two reports are able to diverge in truth value. What (KR) now effectively requires is that Biron have some concept of Katherine that picks out Rosaline at each of his belief worlds, whereas what (RK) requires is that he have some concept of Rosaline that picks out Katherine at each of his belief worlds. These are distinct requirements, and Biron could satisfy one without satisfying the other.

The concept $\lambda w$ [the wearer of the Rosaline-favor in $w$ ] (i.e., the favor which Rosaline was expected to wear to the ball), for example, is a concept Biron has that is actually of Katherine, and that picks out Rosaline at each of his belief worlds, as required by (KR). It doesn't follow from this, however, that he also has a concept of Rosaline that picks out Katherine at each of his belief worlds. He does have the concept $\lambda w$ [the wearer of the Katherine-favor in $w$ ] which picks out Katherine at his belief worlds; but this concept is not of Rosaline, as would be required by (RK) - it is rather of Maria, since she is the one who disguised herself as Katherine.

One might protest at this juncture. Consider again the concept $\lambda w$ [the wearer of the Katherine-favor in $w]$, call it $m$ for short. It doesn't fulfill the role required by $(\mathrm{RK})$, since it doesn't pick out Rosaline at the actual world. But it's easy enough to construct a concept $m^{\prime}$ on the basis of our $m$ that fits the bill, using a recipe set out by Kripke (2011). Take some false proposition $p$ that Biron believes and now consider the concept: 
$\lambda w$ [the $x$ such that $(x=m(w)$ if $p)$ and $(x=$ Rosaline if $\neg p)$ ]

It picks out what $m$ does at $p$ worlds (wearers of the Katherine-favor) and Rosaline at not- $p$ worlds. Since all of Biron's belief worlds are $p$ worlds (he believes $p$ ) and the actual world is a not- $p$ world ( $p$ is false), this concept $m^{\prime}$ fits the bill: it picks out Katherine at his belief worlds (just like $m$ ) and Rosaline at the actual world. So if we grant that Biron has this concept $m^{\prime}$ in his conceptual repertoire, it looks like (RK) will be true after all.

The neo-Kaplanian need not be particularly troubled by this construction, however. The nature of the relation $R$ and the requirements it places on conceptual transformers-and thus on the concepts eligible to witness the truth of belief reports-is a flexible (perhaps even contextually variable) component of the neo-Kaplanian theory and can be adjusted as needed. In particular, there is no need to construe $R$ so loosely as to admit gerrymandered concepts like $m^{\prime}$ as eligible witnesses to the truth of de re belief reports. For example, even if $m^{\prime}$ is in some broad sense available to Biron and an element of his conceptual repertoire, it presumably plays no appreciable role in his cognitive economy or behavioral dispositions and could be ruled ineligible on those grounds. To emphasize the role of $R$, it may be better to speak of $R$-suitable concepts: (KR) requires that Biron have an $R$-suitable concept of Katherine that picks out Rosaline at his belief worlds, and (RK) that he have an $R$-suitable concept of Rosaline that picks out Katherine at his belief worlds. And again, there's no need for the neo-Kaplanian to construe $R$-suitability so loosely as to allow gerrymandered concepts like our $m^{\prime}$ to pass muster.

Our neo-Kaplanian attitude semantics thus accounts for the nonequivalence of (KR) and (RK) while retaining a Millian semantics for names. The Masked Ball therefore does not, pace Cumming (2008), undermine the Millian position. This is not to say that Cumming (2008) wasn't on to an important point. His charge against the Millian runs as follows:

I say that a name is read de dicto* if it appears in the semantic scope of an operator like thinks, and $d e r e^{*}$ otherwise. To establish the nonequivalence of (RK) and (KR), we must make truth-conditional hay out of the de re $/$ de dicto* distinction. As in the case of descriptions, the box operator associated with 'thinks' must shift a parameter to which names are sensitive. Millians, for whom names are insensitive, cannot distinguish de re from de dicto* readings, and so do not have the semantic resources to explain these data. (Cumming 2008: 531)

What is quite right is that in order to establish the nonequivalence of (KR) and (RK), the semantic value of 'thinks' or 'believes' cannot just shift the world of evaluation, as on the textbook semantics-though there are, again, other phenomena, like Double Vision, that also serve to make this point. Where the argu- 
ment goes off track is with the claim that the Masked Ball forces us to conclude, against the Millian, that names must be sensitive to the further parameter shifted by 'believes'. What we need, given the neo-Kaplanian semantics, is that a name be capable of occurring outside the scope of 'believes' while binding a trace, or variable, in the scope of 'believes'. It is this trace, and not the name, that will then be sensitive to the assignment shift effected by the attitude verb. ${ }^{18}$

\section{Triviality Threats}

By way of conclusion, let me address an objection that Pickel (2015) presses against Cumming's attitude semantics and illustrate how the neo-Kaplanian avoids it. Pickel levels the charge that on Cumming's view, we can infer:

from Michael's falsely believing of someone that she is charitable, that he also truly believes of someone that she is charitable. So just by having a false belief that one individual is charitable, Michael thereby has the true belief of a different charitable individual that this individual is charitable. We should not be able to infer that Michael has this very specific true belief from the fact that he has a false belief that someone is charitable. So [Cumming's] account should be rejected. (Pickel 2015. 11)

The argument runs as follows. Let us suppose first that Michael believes some non-charitable individual to be charitable, and second that there is some charitable individual, or as Cumming would regiment these:

$$
\begin{aligned}
& \text { (24) } \exists x\left(\neg C x \wedge \Sigma u\left(u=x \wedge \nabla_{M} C u\right)\right) \\
& \text { (25) } \exists z C z
\end{aligned}
$$

Both of these, we are supposing, are true at the contextually provided assignment $g$. Now let $b$ be the non-charitable witness to (24). Thus both ' $\neg C x^{\prime}$ and ' $\Sigma u\left(u=x \wedge \nabla_{M} C u\right)^{\prime}$ are true on $g\left[{ }^{\prime} x^{\prime} \mapsto b\right]$. Given that the latter, substitutionally quantified statement is true on this assignment, it follows that there must be some variable, say ' $y$ ', such that both ' $y=x^{\prime}$ and:

18. This is of course not to say that variabilism must be rejected, just that the Masked Ball doesn't suffice to establish it. Indeed, it would be straightforward to combine the neo-Kaplanian semantics I've here articulated with a variabilist treatment of names. This would allow names that occur in situ, within the scope of 'believes', to be interpreted via concepts as well. One potential benefit of taking this route is that it might let us implement a version of Cumming's (2008) variabilist account of Frege's Puzzle. However, developing such a solution to Frege's Puzzle in full generality, and showing it superior to extant Millian approaches-such as those put forward by McKay (1981), Salmon (1986), Soames (1987), Braun (1998), and Saul (2007), among others-is a substantial project unto its own, which I leave for another occasion. 
(26) $\triangleright_{M} C y$

are true on $g\left[{ }^{\prime} x^{\prime} \mapsto b\right]$. Importantly, however, (26) is a closed sentence on Cumming's view, since the variable ' $y$ ' is implicitly bound by the assignments quantified over by the operator ' $\square{ }_{M}$ '. This means that (26) is true on any assignment, not just on $g\left[{ }^{\prime} x^{\prime} \mapsto b\right]$. It follows that the following is also true on any assignment:

(27) $y=y \wedge \triangleright_{M} C y$

in view of the fact that both conjuncts are. Thus there is a variable, namely ' $y$ ', to witness the truth of the following substitutionally quantified claim:

(28) $\Sigma u\left(u=y \wedge \unrhd_{M} C u\right)$

which is again true on any assignment. This is bad news: it means that (28) is true no matter what individual is assigned to ' $y$ '.

In particular, let $c$ be the charitable individual that witnesses the truth of (25) from above. Thus ' $C y^{\prime}$ will be true on $g\left[{ }^{\prime} y\right.$ ' $\left.\mapsto c\right]$ as will (28), since the latter is, again, true on any assignment. This in turn means that the following:

(29) $C y \wedge \Sigma u\left(u=y \wedge \varpi_{M} C u\right)$

is true on $g\left[{ }^{\prime} y^{\prime} \mapsto c\right]$, since both conjuncts are, with the consequence that:

(30) $\exists y\left(C y \wedge \Sigma u\left(u=y \wedge \triangleright_{M} C u\right)\right)$

is true on our original assignment $g$. So from the fact that (24) and (25) are true on $g$, we have inferred that (30) is also true on $g$.

I've remarked on a number of similarities between our neo-Kaplanian proposal and Cumming's view, so it is worth considering how the neo-Kaplanian view fares when it comes to Pickel's objection. As it turns out, it avoids it. The crucial step in Pickel's argument is the observation that ' $\square_{M} C y$ ' is a closed sentence. This results from two features of Cumming's view. First, that the operator $' \square_{M}$ ' is a quantifier of world-assignment pairs. This means that any variable within the scope of this operator is evaluated with respect to those assignments rather than the "global" assignment, that is, the assignment relative to which ' $\square{ }_{M} C y$ ' as a whole is evaluated. Second, which assignments ' $\square_{M}$ ' quantifies over is fixed independently of the nature of the global assignment. A change in the nature of the global assignment, in other words, has no effect on the set of worldassignment pairs quantified over by the operator ' $\square{ }_{M}$ '. This renders the attitude ascription ' $\square{ }_{M} C y$ ' a closed sentence: if it is true relative to one assignment, it's true relative to any assignment.

The neo-Kaplanian proposal blocks Pickel's triviality problem because it does not share this second aspect of Cumming's view. Take the following de re report: 
(31) [Some uncharitable individual [ 1 [Michael believes $t_{1}$ is charitable]]]

which says that some uncharitable individual is such that Michael thinks that individual is charitable, along the lines of (24). On the neo-Kaplanian proposal, the embedded clause paralleling (26) from above:

(32) Michael believes $t_{1}$ is charitable.

now is sensitive to the assignment with respect to which its evaluated. For (31) to be true on an assignment $g$, there again has to be some uncharitable individual $b$ such that the embedded $(32)$ is true on $g[1 \mapsto b]$. This requires that Michael have some concept of $b$ which picks out a charitable individual at each of his belief worlds. But now consider an assignment $g[1 \mapsto c]$ which, as before, instead maps 1 to a charitable individual $c$, that is, someone other than $b$. It does not follow that (32) is true with respect to this alternative assignment $g[1 \mapsto c]$, since this now requires that Michael possess a concept of $c$ (rather than one of $b$ ) that picks out a charitable individual at each of his belief worlds. ${ }^{19}$

The neo-Kaplanian proposal can be construed as treating 'believes' as a quantifier over world-assignment pairs, much like Cumming's '๑'. For given a "global" assignment $g$, any belief world $w$ can be paired with the assignment $f(g)^{w}$, the relativization of the conceptual transform $f(g)$ to that belief world. A belief report is then true on $g$, according to the neo-Kaplanian, if the complement of 'believes' is true relative to every such pair $\left\langle w, f(g)^{w}\right\rangle$. But despite these formal similarities, there are crucial differences between the proposal, as Pickel's argument serves to show. In particular, the assignment $f(g)^{w}$ that a given belief world $w$ is paired with has to bear a certain relation to the global assignment $g$ relative to which the report as a whole is evaluated: it has to be the relativization of a conceptual transform of that global assignment. Due to this link between the global assignment and the assignments relative to which the complement of 'believes' is evaluated, (32) is not reduced to a closed sentence as it would be on Cumming's view. It remains an open sentence that imposes substantive constraints on the assignment: it is true on $g$ only if Michael has a concept of the individual $g(1)$ that picks out a charitable individual at each of his belief worlds.

19. One could attempt to re-generate the triviality threat by appeal to gerrymandered concepts of the sort discussed in relation to the Masked Ball reports above. In particular, suppose Michael has a concept $m$ that is of $b$ and that picks out a charitable individual at each of his belief worlds, and that there is some false proposition $p$ that holds across his belief worlds. The concept $\lambda w$ [the unique $x$ such that $(x=m(w)$ if $p)$ and $(x=c$ if $\neg p)$ ] would then be a concept of $c$ that picks out an charitable individual at each of his belief worlds. But as discussed earlier, the neo-Kaplanian need not construe the notion of an $R$-suitable concept so loosely as to allow gerrymandered concepts like this to witness the truth of de re reports. 


\section{Conclusion}

Let me summarize. We began with Cumming's (2008) observation that Millianism, paired with the textbook semantics for 'believes', fails to account for the nonequivalence of the Masked Ball reports. This led Cumming to instead propose a variabilist treatment of names together with a semantics for 'believes' on which it shifts not just the world of evaluation but also the variable assignment. I've argued that the Masked Ball is amenable to a less radical solution. The textbook semantics invoked in Cumming's argument against the Millian faces difficulties for independent reasons, having to do with Double Vision. With a view towards addressing this latter problem I developed an alternative semantics along lines suggested by Kaplan (1968). This proposal also has 'believes' effecting a shift in the assignment function, but it allows us to resolve the Masked Ball problem without having to take the further step of abandoning Millianism and treating names as sensitive to this assignment shift. Finally, I showed that the appeal to conceptual transformers allows the neo-Kaplanian to avoid the triviality problem Pickel (2015) presses against Cumming's attitude semantics.

\section{Appendix}

I here fill in the details of the semantics presented in Section 5 of the paper. Recall that the neo-Kaplanian proposes the following lexical entry for 'believes';

$$
\llbracket \text { believes } \rrbracket^{w, g}=\lambda p_{\langle\gamma,\langle s, t\rangle\rangle} \cdot \lambda x\left[\exists f: \mathrm{R}(f, x, w) \wedge \forall w^{\prime} \in B_{x}^{w}: p\left(f(g)^{w^{\prime}}\right)\left(w^{\prime}\right)=1\right]
$$

As noted earlier, the first argument $p$ of the denotation of 'believes' (corresponding to the complement clause) is an open proposition, that is, a function from assignments and worlds to truth values (with $\gamma$ and $s$ the type of assignments and worlds, respectively) rather than one from just worlds to truth values. Since clauses are of type $t$, we will need to do something to generate the higher type $\langle\gamma,\langle s, t\rangle\rangle$ demanded by our entry. We can do this via a generalization of the Rule of Intensional Functional Application. Whereas IFA introduces an abstractor over just the world parameter of the index, we can generalize it to introduce abstractors over all parameters of the index, including the assignment. ${ }^{20}$ On the simplifying assumption that the index consists of only a world and an assignment, the rule runs as follows: ${ }^{21}$

20. For IFA, see Heim and Kratzer 1998: Section 12.3). There's an unfortunate terminological collision here in two common uses of 'index'. I generally talk of 'variable indices' or 'numerical indices' when talking about the subscripts of variables, and simply 'indices' when talking about the tuples to which the interpretation function is relativized.

21. Compare the rule of "Monstrous Functional Application" discussed by Santorio (2012), though Santorio seems to propose his rule as a supplement to, rather than a replacement of, 
Generalized Intensional Functional Application (GIFA): if $\alpha$ is a branching node and $\{\beta, \gamma\}$ the set of its daughters, then, for any world $w$ and assignment $g$, if $\llbracket \beta \rrbracket^{w, g}$ is a function whose domain contains $\lambda g^{\prime} \cdot \lambda w^{\prime} \llbracket \gamma \rrbracket^{w^{\prime}, g^{\prime}}$, then $\llbracket \alpha \rrbracket^{w, g}=\llbracket \beta \rrbracket^{w, g}\left(\lambda g^{\prime} \cdot \lambda w^{\prime} \llbracket \gamma \rrbracket^{w^{\prime}, g^{\prime}}\right)$

Calling this a generalization of IFA is meant to highlight that it can be used in place of the latter quite generally, in application to shifty operators besides 'believes'. Different kinds of operators just "target" different parameters of the index. A metaphysical necessity modal could, for instance, be given the following denotation:

(34) $\llbracket$ Necessarily $\rrbracket^{w, g}=\lambda p_{\langle\gamma,\langle s, t\rangle\rangle}\left[\forall w^{\prime}\left(w R w^{\prime} \rightarrow p(g)\left(w^{\prime}\right)=1\right)\right]$

This operator differs from 'believes' in that it only "targets" the world parameter of the index, leaving the assignment untouched. Indeed, even variable binders can be handled so as to exploit GIFA (rather than the rule of Predicate Abstraction used by Heim and Kratzer 1998). Rabern (2013) suggests that binders could be given denotations of the following sort (adapted to the present framework, with $i$ standing for a numerical index): ${ }^{22}$

$$
\llbracket i \rrbracket^{w, g}=\lambda p_{\langle\gamma,\langle s, t\rangle\rangle} \cdot \lambda x[p(g[i \mapsto x])(w)]
$$

We can again use GIFA to generate the needed $\langle\gamma,\langle s, t\rangle\rangle$ type argument. The binder differs from 'believes' in that it (i) targets only the assignment, leaving the world untouched, and (ii) modifies the assignment at only a single variable index, rather than performing a global transformation.

The derivation of truth conditions for example (15a) from earlier now proceeds as follows (using GIFA to deal with both 'believes' and the variable binder ' 1 '):

1. $\llbracket\left[\right.$ Ortcutt [ 1 [ Ralph believes $t_{1}$ is a spy ] ] ] $\rrbracket^{w, g}=1$ iff

2. By the proposed lexical entry for predicate abstractors, together with GIFA:

$\lambda p_{\langle\gamma,\langle s, t\rangle\rangle} \cdot \lambda x[p(g[1 \mapsto x])(w)]\left(\lambda g^{\prime \prime} . \lambda w^{\prime \prime} \llbracket\right.$ Ralph believes $t_{1}$ is a spy $\left.\rrbracket^{w^{\prime \prime}, g^{\prime \prime}}\right)$

$\left(\llbracket\right.$ Ortcutt $\left.\rrbracket^{w, g}\right)=1$ iff

$\lambda g^{\prime \prime} \cdot \lambda w^{\prime \prime} \llbracket$ Ralph believes $t_{1}$ is a spy $\left.\rrbracket^{w^{\prime \prime}, g^{\prime \prime}}\right)(g[1 \mapsto o])(w)=1$ iff

3. $\llbracket$ Ralph believes $t_{1}$ is a spy $\rrbracket^{w, g[1 \mapsto o]}=1$ iff

4. By GIFA:

to the rule of Intensional Functional Application. A compositional rule of this form is also discussed by Rabern (2012).

22. See also Lewis (1970). 
$\llbracket$ believes $\rrbracket^{w, g[1 \mapsto o]}\left(\lambda g^{\prime \prime} . \lambda w^{\prime \prime} \llbracket t_{1}\right.$ is a spy $\left.\rrbracket^{w^{\prime \prime}, g^{\prime \prime}}\right)\left(\llbracket \operatorname{Ralph} \rrbracket^{w, g[1 \mapsto o]}\right)=1$ iff

5. By the lexical entries for 'believes' and 'Ralph':

$$
\begin{aligned}
& \lambda p_{\langle\gamma,\langle s, t\rangle\rangle} \cdot \lambda x\left[\exists f: \mathrm{R}(f, x, w) \wedge \forall w^{\prime} \in B_{x}^{w}: p\left(f(g[1 \mapsto o])^{w^{\prime}}\right)\left(w^{\prime}\right)=1\right] \\
& \left(\lambda g^{\prime \prime} . \lambda w^{\prime \prime} \llbracket t_{1} \text { is a spy } \rrbracket^{w^{\prime \prime}, g^{\prime \prime}}\right)(R a l p h)=1 \text { iff }
\end{aligned}
$$

6. $\exists f: R(f$, Ralph,w $) \wedge \forall w^{\prime} \in B_{\text {Ralph }}^{w}: \lambda g^{\prime \prime} \cdot \lambda w^{\prime \prime} \llbracket t_{1}$ is a spy $\rrbracket^{w^{\prime \prime}, g^{\prime \prime}}(f(g[1 \mapsto$ $\left.o])^{w^{\prime}}\right)\left(w^{\prime}\right)=1$ iff

7. $\exists f: R(f, R a l p h, w) \wedge \forall w^{\prime} \in B_{\text {Ralph }}^{w}: \llbracket t_{1}$ is a spy $\rrbracket^{w^{\prime}, f(g[1 \mapsto o])^{w^{\prime}}}=1$ iff

8. $\exists f: R(f, R a l p h, w) \wedge \forall w^{\prime} \in B_{R a l p h}^{w}: \operatorname{Spy}\left(f(g[1 \mapsto o])^{w^{\prime}}(1), w^{\prime}\right)$ iff

9. By Relativization:

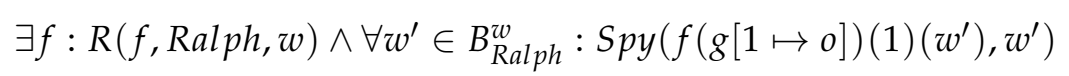

Another point I should like to comment on concerns the way in which I have-following Cumming (2008) and, more distantly, Quine (1956) - been treating the de re/de dicto distinction in terms of a scope ambiguity. This scopal analysis of the distinction is controversial. One classic objection, due to May (1977), involves the following pair: ${ }^{23}$

(36) a. Some politician will address every rally in John's district.

b. Some politician thinks that he will address every rally in John's district.

May observes that whereas (36a) has a reading on which the universal 'every rally' has wide scope over the existential 'some politician', the belief report (36b) does not have a reading where politicians vary with the rallies. The conclusion drawn by May and others is that the clausal complement to 'thinks' (and indeed finite clauses in general) is a scope island, and that de re readings of phrases under 'thinks' therefore cannot be the result of their taking wide scope over the attitude verb. ${ }^{24}$

23. See Keshet and Schwarz (2014) for a detailed critical discussion of the traditional scopal account of the de re/de dicto distinction. Example (36) is taken from von Fintel and Heim (2011). 24. That said, there are potentially confounding data. Take the following:

(i) a. Some teacher thinks each student cheated.

b. A different teacher thinks each student cheated.

To my ear, (ia) has a reading on which the teachers vary with the students. This reading becomes more salient if we insert 'different', as in (ib) though there is a reading of (ib) on which we're talking about a particularly suspicious teacher (one who is different from some contextually salient teacher), another reading is one on which the suspicious teacher differs from student to student. To accommodate this reading, we would have to allow 'each student' to take scope over the existential subject, and thus over the attitude verb 'thinks'. 
The proposal I've here laid out does not, however, strictly require the traditional scopal account. In particular, it can also be implement in a version of the "split-intensionality" proposal that Keshet (2011) has developed in response to the problems faced by the scopal account. The heart of Keshet's proposal is the introduction of an operator ${ }^{\wedge}$ immediately below 'thinks'. Phrases occurring below this operator are interpreted relative to belief worlds, whereas phrases occurring above it are interpreted relative to the original world of evaluation (i.e., the one with respect to which 'thinks' itself is evaluated). With this operator in place, a phrase in the complement to 'thinks' can then move to a position above the operator to receive a de re interpretation, while still remaining below 'thinks' itself, thereby respecting the scope island constraint.

For the de re reading of 'Ralph thinks Ortcutt is a spy' we would, for example, have the following syntax:

(37) Ralph thinks [Ortcutt [ $1\left[^{\wedge}\left[t_{1}\right.\right.$ is a spy $\left.\left.\left.]\right]\right]\right]$

On the semantic side, we can assign Keshet's ${ }^{\wedge}$ operator the following denotation: 25

$$
\llbracket^{\wedge} \rrbracket^{w, g}=\lambda p_{\langle\gamma,\langle s, t\rangle\rangle} \cdot \lambda h \cdot \lambda w^{\prime}\left[p\left(h(g)^{w^{\prime}}\right)\left(w^{\prime}\right)\right]
$$

The first argument $p$ is again a function from assignments and worlds to truth values (an "open proposition"). The second argument $h$ is a conceptual transformer, and the third argument $w^{\prime}$ is a belief world. This second and third argument are passed to ${ }^{\wedge}$ by the semantic value of 'believes', which would now look as follows:

$$
\llbracket \text { believes } \rrbracket^{w, g}=\lambda p_{\langle\sigma,\langle s, t\rangle\rangle} \cdot \lambda x\left[\exists f: R(f, x, w) \wedge \forall w^{\prime} \in B_{x}^{w}: p(f)\left(w^{\prime}\right)=1\right]
$$

with $\sigma$ being the type of conceptual transformers. To derive truth the truth conditions of (37) we begin with the complement to 'thinks':

1. $\llbracket\left[\right.$ Ortcutt $\left[1\left[\wedge\left[t_{1}\right.\right.\right.$ is a spy $\left.\left.\left.]\right]\right]\right] \rrbracket^{w, g}=$

2. By the proposed entry for predicate abstractors and GIFA:

$$
\begin{aligned}
& \lambda p_{\langle\gamma,\langle s, t\rangle\rangle} \cdot \lambda x[p(g[1 \mapsto x])(w)]\left(\lambda g^{\prime \prime} . \lambda w^{\prime \prime} \llbracket\left[{ }^{\wedge}\left[t_{1} \text { is a spy }\right]\right] \rrbracket^{w^{\prime \prime}, g^{\prime \prime}}\right) \\
& \left(\llbracket \text { Ortcutt } \rrbracket^{w, g}\right)=
\end{aligned}
$$

3. $\lambda g^{\prime \prime} \cdot \lambda w^{\prime \prime}\left[\llbracket^{\wedge}\left[t_{1}\right.\right.$ is a spy $\left.] \rrbracket^{w^{\prime \prime}, g^{\prime \prime}}\right](g[1 \mapsto o])(w)=$

4. $\mathbb{\llbracket}^{\wedge}\left[t_{1}\right.$ is a spy $] \rrbracket^{w, g[1 \mapsto o]}=$

5. By the entry for the ${ }^{\wedge}$ operator and GIFA:

25. Compare (Keshet 2011 264). My adaptation of the proposal departs from Keshet in two respects: first, whereas Keshet has ${ }^{\wedge}$ combine with something of type $\langle s, t\rangle$ (i.e., a proposition), I have it combine with something of type $\langle\gamma,\langle s, t\rangle\rangle$ (an open proposition), and whereas Keshet formulates a special compositional rule ("Intensional Abstraction") for ${ }^{\wedge}$, I assign it a denotation and again let GIFA do the compositional work. 


$$
\lambda p_{\langle\gamma,\langle s, t\rangle\rangle} \cdot \lambda h \cdot \lambda w^{\prime \prime}\left[p\left(h(g[1 \mapsto o])^{w^{\prime \prime}}\right)\left(w^{\prime \prime}\right)\right]\left(\lambda g^{\prime \prime \prime} \lambda w^{\prime \prime \prime}\left[\llbracket\left[t_{1} \text { is a spy }\right] \rrbracket^{w^{\prime \prime \prime}, g^{\prime \prime \prime}}\right]\right)=
$$

6. $\lambda h \cdot \lambda w^{\prime \prime}\left[\llbracket t_{1}\right.$ is a spy $\left.\rrbracket^{h(g[1 \mapsto o])^{w^{\prime \prime}}, w^{\prime \prime}}\right]=$

7. $\lambda h \cdot \lambda w^{\prime \prime}\left[\operatorname{Spy}\left(h(g[1 \mapsto o])^{w^{\prime \prime}}(1), w^{\prime \prime}\right)\right]$

Using this we now calculate the truth conditions for the whole sentence:

8. $\llbracket$ Ralph thinks [Ortcutt $\left[1\left[\wedge\left[t_{1}\right.\right.\right.$ is a spy $\left.\left.\left.\left.]\right]\right]\right]\right]^{w, g}=1$ iff

9. $\llbracket$ thinks $\rrbracket^{w, g}\left(\llbracket\left[\right.\right.$ Ortcutt $\left[1\left[^{\wedge}\left[t_{1}\right.\right.\right.$ is a spy $\left.\left.\left.\left.]\right]\right]\right] \rrbracket^{w, g}\right)\left(\llbracket \operatorname{Ralph} \rrbracket^{w, g}\right)=1$ iff

10. By the entries for 'believes' and 'Ralph', and the derivation above:

$\lambda p_{\langle\sigma,\langle s, t\rangle\rangle} \cdot \lambda x\left[\exists f: R(f, x, w) \wedge \forall w^{\prime} \in B_{x}^{w}: p(f)\left(w^{\prime}\right)=1\right]\left(\lambda h \cdot \lambda w^{\prime \prime}[\operatorname{Spy}(h(g[1 \mapsto\right.$ $\left.\left.\left.o])^{w^{\prime \prime}}(1), w^{\prime \prime}\right)\right]\right)($ Ralph $)=1$ iff

11. $\exists f: R(f, R a l p h, w) \wedge \forall w^{\prime} \in B_{\text {Ralph }}^{w}: \lambda h \cdot \lambda w^{\prime \prime}\left[\operatorname{Spy}\left(h(g[1 \mapsto o])^{w^{\prime \prime}}(1), w^{\prime \prime}\right)\right](f)\left(w^{\prime}\right)$ $=1 \mathrm{iff}$

12. $\exists f: R(f, R a l p h, w) \wedge \forall w^{\prime} \in B_{R a l p h}^{w}: \operatorname{Spy}\left(f(g[1 \mapsto o])^{w^{\prime}}(1), w^{\prime}\right)$ iff

13. By Relativization:

$$
\exists f: R(f, \text { Ralph }, w) \wedge \forall w^{\prime} \in B_{\text {Ralph }}^{w}: \operatorname{Spy}\left(f(g[1 \mapsto o])(1)\left(w^{\prime}\right), w^{\prime}\right)
$$

\section{Acknowledgments}

Many thanks to Simon Charlow, Sam Cumming, Jan Dowell, Wesley Holiday, Peter Jenks, Richard Lawrence, Harvey Lederman, Mike Martin, Seth Yalcin, two anonymous referees and an Area Editor from Ergo, a referee from another journal, as well as audiences at the $6^{\text {th }}$ California Universities Semantics and Pragmatics Conference, UC Berkeley, Magdalen College Oxford, Syracuse University, the $5^{\text {th }}$ Cornell Workshop in Linguistics and Philosophy, and Harvey Lederman's Spring 2016 Seminar at NYU for helpful comments and suggestions at various stages in this paper's development.

\section{References}

Aloni, Maria (2005). Individual Concepts in Modal Predicate Logic. Journal of Philosophical Logic, 34(1), 1-64.

Bonomi, Andrea (1995). Transparency and Specificity in Intentional Contexts. In Paolo Leonardi and Marco Santambrogio (Eds.), On Quine: New Essays (164185). Cambridge University Press. 
Braun, David (1998). Understanding Belief Reports. The Philosophical Review, 107(4), 555-595.

Charlow, Simon and Yael Sharvit (2014). Bound 'de re' Pronouns and the LFs of Attitude Reports. Semantics $\mathcal{E}$ Pragmatics, 7(3), 1-43.

Cumming, Samuel (2008). Variabilism. Philosophical Review, 117(4), 525-554.

Hawthorne, John and David Manley (2012). The Reference Book. Oxford University Press.

Heim, Irene and Angelika Kratzer (1998). Semantics in Generative Grammar. Blackwell.

Hintikka, Jaakko (1962). Knowledge and Belief: An Introduction to the Logic of the Two Notions. Cornell University Press.

Holliday, Wesley H. and John Perry (2014). Roles, Rigidity, and Quantification in Epistemic Logic. In Alexandru Baltag and Sonja Smets (Eds.), Johan van Benthem on Logic and Information Dynamics (591-629), Vol. 5 of Outstanding Contributions to Logic. Springer.

Kaplan, David (1968). Quantifying In. Synthese, 19(1/2), 178-214.

Keshet, Ezra (2011). Split Intensionality: A New Scope Theory of De Re and De Dicto. Linguistics and Philosophy, 33, 251-283.

Keshet, Ezra and Florian Schwarz (2014). De Re/De Dicto. Manuscript in preparation. Retrieved from http://florianschwarz.net/wp-content/uploads/ papers/De_Re__De_Dicto.pdf

Kripke, Saul (2011). Unrestricted Exportation and Some Morals for the Philosophy of Language. In Philosophical Troubles: Collected Papers (Vol. 1, 322-350). Oxford University Press.

Lewis, David (1970). General Semantics. Synthese, 22(1-2), 18-67.

Maier, Emar (2009). Presupposing Acquaintance: A Unified Semantics for de dicto, de re and de se Belief Reports. Linguistics and Philosophy, 32(5), 429-474.

May, Robert (1977). The Grammar of Quantification (Doctoral Dissertation). MIT. Retrieved from https://dspace.mit.edu/handle/1721.1/16287

McKay, Tom (1981). On Proper Names in Belief Ascriptions. Philosophical Studies, 39(3), 287-303.

Ninan, Dilip (2012). Counterfactual Attitudes and Multi-Centered Worlds. Semantics $\mathcal{E}$ Pragmatics, 5(5), 1-57.

Percus, Orin and Uli Sauerland (2003). On the LFs of Attitude Reports. In Matthias Weisgerber (Ed.), Proceedings of Sinn und Bedeutung 7, Volume 114 of Arbeitspapiere des Fachbereichs Sprachwissenschaft (228-242). Universität Konstanz.

Pickel, Bryan (2015). Variables and Attitudes. Noûs, 49(2), 333-356.

Quine, Willard V. (1956). Quantifiers and Propositional Attitudes. The Journal of Philosophy, 53(5), $177-187$.

Rabern, Brian (2012). Against the Identification of Assertoric Content with Com- 
positional Value. Synthese, 189(1), 75-96.

Rabern, Brian (2013). Monsters in Kaplan's Logic of Demonstratives. Philosophical Studies, 164(2), 393-404.

Russell, Bertrand (1903). The Principles of Mathematics. Cambridge University Press.

Russell, Bertrand (1905). On Denoting. Mind, 14(56), 479-493.

Salmon, Nathan (1986). Frege's Puzzle. The MIT Press.

Santorio, Paolo (2012). Reference and Monstrosity. Philosophical Review, $121(3), 359-406$.

Saul, Jennifer (2007). Simple Sentences, Substitutions, and Intuitions. Oxford University Press.

Schlenker, Philippe (2004). Person and Binding (A Partial Survey). Italian Journal of Linguistics, 16(1), 155-218.

Soames, Scott (1987). Direct Reference, Propositional Attitudes, and Semantic Content. Philosophical Topics, 15(1), 47-87.

Sosa, Ernest (1970). Propositional Attitudes De Dictu and De Re. The Journal of Philosophy, 67(21), 883-896.

von Fintel, Kai and Irene Heim (2011). Intensional Semantics. MIT, Lecture Notes. Yalcin, Seth (2015). Quantifying In From a Fregean Perspective. Philosophical Review, 124(2), 207-253. 